\title{
Neuroplasticity and Positive Psychology in Clinical Practice: A Review for Combined Benefits
}

\author{
Joyce Shaffer \\ Department of Psychiatry and Behavioral Sciences, University of Washington, Seattle, USA \\ Email: JShaff@UW.edu
}

Received September $30^{\text {th }}, 2012$; revised November $6^{\text {th }}, 2012$; accepted November $29^{\text {th }}, 2012$

\begin{abstract}
Research on using positive psychological perspectives to drive brain plasticity in a positive direction is increasingly encouraging and empowering for clinicians and clients. Increased lifespan with neuroplastic gains was found by Diamond in lab rats when they were held and spoken to. Improvements in brain chemistry, architecture and performance associated with lifestyle choices are now being documented in humans with increasing frequency of reports. Positive psychology can strengthen this trend toward increases in wellbeing by using this evolving research for motivation to increase healthy lifestyle choices, for reinforcement of successive approximation toward these goals and for the many gains associated with greater happiness.
\end{abstract}

Keywords: Neuroplasticity; Brain Plasticity; Neurogenesis; Aging; Cognitive; Cognition; Computerized Cognitive Training

\section{Introduction}

We need not rest "on the cusp of a revolution, which is set to transform the diagnosis and treatment of mental illness and reverse the lack of major progress made in curbing associated ill health and death over the past 100 years" which was described by our director of NIMH, Thomas Insel. The British Medical Journal (White, 2011) reports that he told the Royal Society in London on 31 August, 2011: "We are at an extraordinary moment when the entire scientific foundation for mental health is shifting, with the 20th century discipline of psychiatry becoming the 21st century discipline of clinical neuroscience." He recommended brain-plasticity based pre-emptive strategies that "could include the development of a credible risk score coupled with some, or all of, cognitive training, psychosocial approaches, education, and the use of specially designed video and computer games". This recommendation finds more than adequate support in the growing body of research in the fields of neuroplasticity and positive psychology.

Neuroplasticity can be defined as the natural tendency of the brain architecture to shift in negative or positive directions in response to intrinsic and extrinsic influences. Positive psychology strives to achieve "a scientific understanding and effective interventions to build thriving individuals, families, and communities" (Seligman \& Csikszentmihalyi, 2000). Indeed, positive psychology "may covertly be a central component of good psychotherapy as it is done now" (Duckworth, Steen, \& Seligman, 2005). The purpose of the paper is to review recent research on neuroplasticity with consideration for the several ways that positive psychologists can facilitate driving brain plasticity in a positive direction at any age

The goal of this review is to add dignity to aging, emphasize science-based ways to enrich heredity, maximize human potential, and enjoy playing a role in evolving human intelligence. Massive gains in human intelligence that have been found across time are referred to as the Flynn Effect (Flynn,
1984, 1987). These findings coupled with recent neuroscience clearly showing the potential for improving brain plasticity (Goh \& Park, 2009) can give humans unprecedented hope for our future. And neuroplasticity has fleshed out what some of these chemical, anatomical and performance gains could include.

Search efforts for this review were primarily focused within the PubMed database and included animal as well as human studies. Articles accepted for review met rigorous scientific standards, almost exclusively were random controlled trials, and were included without a specified time span. Also, bibliographies of these articles and related reviews were searched. Periodic searches of this nature were conducted between 2005 and 2012 using names of prominent researchers in the field as well as combinations of keywords listed above.

\section{Neuroplasticity and Synaptogenesis: Enhancements on a Cellular Basis}

The discussion of neuroplasticity necessarily begins with the work of Marian Diamond. Clinicians and consumers can benefit from reading her books, Enriching Heredity as well as Magic Trees of the Mind.

Showing the role of environmental enrichment in driving brain plasticity in a positive direction was one of her seminal contributions (Diamond et al., 1971; Malkasian \& Diamond, 1971; Uylings et al., 1978). When twelve rats were housed in one large cage and given many objects to play with, their brains were remarkably different from the control group in which each rat was alone in a simple regular cage. After eighty days in their environment, the enriched rats as compared to the controls showed such advantages as a $6 \%$ thicker cerebral cortex as well as dendrites that were longer with more complex branching, spines and synapses. These plastic changes have been associated with enhanced intelligence through executive functions that are faster and more accurate. And offspring of mammals 
afforded enriched environments while in utero had larger brains than their mothers. She also found more glial cells (previously thought to be primarily supportive) per neuron in the brain of Einstein (Diamond et al., 1985).

Diamond's initial assertion that these advantages could be appreciated even in the elderly was refuted by a claim that her 600-day-old rats didn't qualify as elderly. In an effort in her lab to keep rats alive longer, the rats were held and talked to daily (Diamond et al., 1984). This positive psychological approach resulted in the rats surviving 904 days, a 50\% increase in longevity. Diamond calculated that this "was equivalent to a 90 -year-old person" and the positive impact on neuroplasticity was still found. Diamond emphasized that stimulation improved brain anatomy of her animals throughout the lifespan from prenatal to the very elderly. She believed these same changes could be appreciated at any age by humans as well.

This positive psychological approach yielded so much neuroplastic purchase in rats that it can afford a scientific basis for the positive psychology perspective to counter the myth of "the normal decline of aging" with optimism about the potential of aging brain cells and encouragement of continuous active stimulation.

Her research also found importance of stimulating expression of emotions to engage connections between the cerebral cortex and the limbic system including activating the amygdala, hypothalamus and hippocampus. She stated that "emotional wellbeing may be more essential for survival than intellectual".

Diamond's research shows that inheritance does not control our destiny. Others concur. Genetics road maps do not rule the road ahead (Kopinsky et al., 2002).

Active participation is essential to observe changes in the brain. Animals in a separate cage observing the active play of animals in an enriched environment did not show similar brain changes. Thus, these findings can influence the work of positive psychology to emphasize positive emotions and interactions with an enriched environment for everyone "at any age."

Since enrichment for as little as four days was associated with these brain changes, subsequent research focused on changes in the DNA to store new memories when stimulation was frequent and active. Thus neuroplasticity can be described on a behavioral, systemic, cellular or molecular basis. We have the option of active participation to enrich heredity with associated improvements in learning and performance. Positive psychology can emphasize positive emotions and interactions with an enriched environment for everyone "at any age" because this response of the nervous system occurs with stimulation that is extrinsic and intrinsic to support learning and as related to therapy.

Perhaps the world expert on intrinsic neuroplastic impact of positive emotions is Richard Davidson, one of the world's leading neuroscientists.

Impressed by how easily thinking can move a human from healthy to the depth of depression or the flight of terror, he led some of the early research on emotional and brain changes associated with meditation. In collaboration with His Holiness the Dalai Lama, he studied brain function in Buddhist monks that had trained in meditation for varying periods of time. The monks' brains functioned differently when meditating and differently than brains of naïve meditators. With long-term meditation, "tens of thousands of hours," anatomical and functional brain plasticity was noted.

The left prefrontal cortex is the brain part that regulates posi- tive emotions such as happiness. It showed the greatest change with deep meditation and the greatest increase in volume in monks with extended experience (Davidson et al., 2003; Davidson \& Lutz, 2008).

Advances in technology afford greater diversity of brain measures (Eyler et al., 2011). For example, tools such as the MRI have made it possible to observe increased white matter connecting the prefrontal cortex to the amygdala in highly resilient individuals (Kim \& Whalen, 2009). The connections between the hippocampus and other brain structures suggest avenues used for memory storage and retrieval (Ranganath, 2010). Understanding how humans use stronger signals of desired focus and inhibition of distracting variables to focus attention (Lutz et al., 2008) can assist in coping with increasing information overload. The practice of certain forms of meditation can strengthen abiding attention and selective attention (Slagter et al., 2009; Lutz et al., 2008). Magnetoencephalography showed altered brain patterns associated with focused attention after just eight weeks of mindfulness-based stress reduction (Kerr et al., 2001).

Well-being therapy (Fava \& Tomba, 2009) has enhanced various aspects of well-being such as "autonomy, environmental mastery, positive interpersonal relationships, personal growth, purpose in life, and self-acceptance". Davidson (2012) considers it "a good bet that well-being therapy strengthens the prefrontal cortex and its connections with the ventral striatum."

The anterior cingulate cortex is the part of the brain associated with resolving conflict as well as exercising control of cognition and emotion. In research led by Posner (Tang et al., 2012) neural activity of this part of the brain changed and "improved connectivity" with other regions of the brain. The type of therapy used in this study was "integrative body-mind training". Their results found white brain matter changes associated with improvements in self-regulation after four weeks of this training. They believe this greater efficiency of white brain matter might indicate that this intervention could be beneficial for treating or preventing several problems that require selfregulation "including addiction and mental disorders such as attention-deficit hyperactivity disorder, anxiety, depression, schizophrenia, and borderline personality disorder". They posit that the changes in emotional status and autonomic nervous system related to this therapy might be related to the improved white matter efficiency. Thus, short-term meditation can be beneficial for white brain matter neuroplasticity and be beneficial for prevention and treatment of mental disorders that include a component of difficulty with self-regulation.

Clinicians continue to teach a specialized form of mental training with cognitive behavioral techniques (CBT) from a variety of perspectives (Ellis, 1987, 2005; Ellis \& Harper, 1975; Beck, 2006; Burns, 1992, 1999). CBT-related changes in thought patterns have been associated with less activity in the brain's frontal cortex, increased limbic system activity, and much lower relapse rates of major depression than with medications (Goldapple et al., 2004).

That's particularly important since research has shown that positive emotions are associated with health (Danner et al., 2001; Ostir et al., 2000, 2001; Chida \& Steptoe, 2008). Seligman, Rashid \& Parks (2006) found symptomatic improvement in unipolar depression using positive psychotherapy. Use of the internet for a random controlled trial has provided empirical validation of some positive psychology techniques that can increase happiness and decrease depression for as long as six 
months (Seligman et al., 2005). Thus, CBT and other positive psychological interventions are especially significant because the potential damage of the chemistry of depression and stress might be avoided by psychotherapy which has been of similar effect but greater duration than pharmacotherapy (Antonuccio et al., 1999). Duration of depression has been found to be more powerful than age in predicting volume loss in the human hippocampus (Sheline et al., 1999).

In a review of studies of neuroplasticity, Cramer (2011) noted that attention, motivation and activity are essential to plasticity. Techniques found to be associated with positive neuroplasticity included antidepressant medications, stress reduction, social influences, task-specific training, modifying "cognitive representations and behavioural responses to distressing stimuli", computerized cognitive training that is intensely focused on auditory and verbal processing, and targeting a specific brain system. Rabipour \& Raz (2012) provide a review of some cognitive training programs.

Intensive training during adolescence or young adulthood "re-normalized" enduring deficits in auditory cortex processing that had been induced in infant rats (Zhou \& Merzenich, 2009). Merzenich and colleagues (Mahncke et al., 2006) believe that declines in adult human functioning can be reversed, stopped, or reduced. They developed a "brain-plasticity-based training program".

Using this computer-based program that includes positive reinforcement of speed and accuracy (Mahncke et al., 2006a), they conducted a random controlled trial. Eight to ten weeks of training resulted in significant improvement in memory that generalized to other tasks. Some of these gains in verbal memory were still apparent after three months without further training with 182 participants from ages sixty to eighty-seven.

A subsequent trial (Smith et al., 2009) found memory, speed and accuracy gains that generalized to tests on which they received no training. Speed of processing improved from 118 down to 51 milliseconds in this program with individuals between the age of sixty-five and ninety-three.

Their later study (Berry et al., 2010) used visual discrimination with healthy individuals between the ages of sixty and eighty-nine. After ten one-hour sessions using computer software, improvements in working memory for untrained tasks were significant.

Software with similar features as described by Smith (2009) also found benefits of clinical significance (Jobe et al., 2001). The Advanced Cognitive Training for Independent and Vital Elderly (ACTIVE) study (Ball et al., 2002) focused on 2853 participants in diverse settings. This and multiple subsequent studies have found benefits in a variety of realms such as increased useful field of view (Edwards et al., 2006), driving (Roenker et al., 2003; Ball et al., 2006) and health related quality of life as well as depression (Wolinsky et al., 2006).

Cognitive improvements associated with increased focal brain volume have also been found in women "with amnestic mild cognitive impairment" (Baker et al., 2010). Participants between the ages of fifty-five and eighty-five that maintained 45 to 60 minutes of aerobic activities four times a week for six months appreciated improved "executive control processes. Numerous other studies have also found brain volume changes associated with cognitive gains after aerobic exercise (Erickson et al., 2009, 2010, 2011; Heo et al., 2009; Flicker et al., 2010; Prakash et al., 2011).

One research study found good results using this combina- tion brilliantly in a concept they call "exergaming" (AndersonHanley et al., 2012). This random controlled clinical trial studied the impact of three months of traditional exercise versus stationary cycling with virtual reality tours ("cybercycle") on executive function in 102 older adults with mild cognitive impairment. Since the cybercyclists showed greater cognitive improvement, the researchers suggest that "simultaneous cognitive and physical exercise has greater potential for preventing cognitive decline". It would have added interest if assessments of brain changes were also reported.

\section{Neurogenesis: A Special Form of Neuroplasticity}

Proof of neurogenesis in humans (Eriksson et al., 1998) at any age marked a milestone in brain plasticity (Gage, 2002). Gage and colleagues (Pereira et al., 2007) found evidence of increased neurogenesis in eleven human beings that were below average in aerobic fitness prior to the study. Participants were aerobic four times a week for twelve weeks. The increase in neurogenesis was noted in the part of the hippocampus that is associated with learning and memory as well as age-related cognitive decline. Participants showed improved performance on the Rey Auditory Verbal Learning Test that was correlated with improvements in VO2Max, the gold standard measure of aerobic fitness.

Making maximum purchase of neuroplasticity is "one promising avenue to reach the goal of successful aging" (Jessberger \& Gage, 2008). Since "approximately 30\% - 40\%" of new neurons survive to integrate, simply increasing the birth rate may under-realize this neuroplastic potential. While aerobic exercise increases the number of new neurons in humans and other animals, survival and stable integration is dependent on other factors (Snyder et al., 2009).

Gage and colleagues (Kempermann et al., 2002) corroborated plasticity in elderly rats. Rats from the age of ten to twenty months were already middle-aged at the beginning of the study and elderly by its completion. Enrichment included complex inanimate as well as social stimulation. Rats in an enriched environment increased sustained neurogenesis fivefold in comparison to the control group that was housed in standard cages. Even more encouraging, this "neuroplasticity in old age" was associated with "significant improvements of learning parameters, exploratory behavior, and locomotor activity." For example, their spatial memory improved. Perhaps best of all, reduced amounts of lipofuscin in their hippocampal neurons indicated "decreased nonspecific age-dependent degeneration" of their brain cells! In essence, their activity demonstrated not just immediate "but also a sustained effect on brain plasticity".

Taken together, we have a human model for increasing neurogenesis with aerobic activity (Pereira et al., 2007). Rats give us an animal model for sustained neurogenesis that increased fivefold with complex stimulation that is both social and inanimate. These and other studies provide additional encouragement for positive lifestyle choices by also showing cognitive gains with this plastic response (Audiffren et al., 2008). And the rat study can add the motivation of "decreased nonspecific age-dependent degeneration" as measured by less accumulation of lipofuscin in hippocampal neurons.

Sleep deprivation and untreated depression in animals (Guzman-Marin et al., 2006) have been shown to decrease neurogenesis. However, depressed people can experience an elevated mood for at least one day after missing one night of sleep. 
Antidepressants restored neurogenesis in lab animals. To study this interesting complex of data further, rats were kept awake while being handled gently during the twelve hours they would normally sleep (Zucconi et al., 2006). In comparison to the control group of rats that were permitted to sleep, rats with gentle handling in one night of sleep deprivation had significantly increased neurogenesis in the hippocampus as well as increased survival of these new neurons fifteen and even thirty days after their sleepless night. No differences were noted in their subventricular zone of the lateral ventricles, the other identified site of neurogenesis in mammalian brains.

The immune response can have a negative or positive influence on neurogenesis (Kohman \& Rhodes, 2012; Sartori et al., 2012). While inflammation, an immune response, can reduce neuron birth, survival, function and integration, in a healthy brain it can enhance these stages of neurogenesis by being a brief healing response to infection or cerebral insult. However, inflammation has been found to increase with age. Neuroinflammation and impaired learning memory were found in rodents when their sleep was disturbed (Zhu et al., 2012). Since chronic inflammation is a risk factor for dementia, monitoring for it could assist in maintaining brain health (Rosano et al., 2012).

\section{Discussion}

In keeping with the recommendations of Thomas Insel, these and other studies can be used in clinical practice to educate, motivate and reinforce consumers in efforts to "build thriving individuals, families and communities" as is the goal of positive psychology (Seligman \& Csikszentmihalyi, 2000). Adding new brain cells by virtue of one's own lifestyle choices could be a more powerful incentive than we often have to offer. That's especially true when these findings have been associated with improved cognition in animals and in humans; with continued neuroplastic as well as cognitive gains across the lifeline of rats that lived fifty percent longer in enrichment; and with fivefold increase in neurogenesis associated with significant cognitive gains in rats afforded enriched environments.

A review and meta-analysis (Colcombe \& Kramer, 2003) of eighteen intervention studies found robust but selective cognitive benefits with fitness training. Of these fitness-induced gains, "executive-control processes" showed the largest benefits. Included in this are planning, inhibition and scheduling of mental procedures. Their answer to the question of whether "aerobic fitness training can have a robust and beneficial influence on cognition of sedentary older adults" was "an unequivocal yes". Individuals who had maintained a high level of fitness across time showed better performance than older individuals that had a low level of fitness. A later review supports this (Angevaren et al., 2008). However, very few people maintain even this minimum amount of aerobic activity. This is also important since chronic inflammation is a risk factor for dementia and aerobic exercise can help reduce inflammation. Thus, it bears repeating that this might be an ideal place for the application of positive psychological techniques to increase frequency of this lifestyle choice.

Sleep is another critical brain variable. It can be improved by cognitive behavioral techniques (Gregg et al., 2004), can enhance inspired insight (Wagner, 2004) and is necessary for memory consolidation (Stickgold, 2005).

When they learn that lifestyle choices can enhance their brain function as well as prolong their life, many people are more inclined to do at least some of those things that can make the combined purchase. Thus, this education coupled with strategic positive psychological practices including reinforcement, celebration and increasing happiness could address the essential goal of changing the field of mental health in ways that can reduce the related healthcare burden (Lojovich, 2010).

It is significant that exercise and some forms of cognitive training target the brain sites considered most vulnerable to the so-called "normal decline of aging". Since these types of intervention have shown gains in the chemistry, architecture and performance of human and other animal brains, the call of Thomas Insel to facilitate the profound shift in how we promote enhancing mental health is timely, perhaps even urgent with the global trend of humans living longer.

Advantages of computer based programs include the greater accuracy and efficiency of positive reinforcements for successive approximations than could ever be applied by even the best and brightest humans. Use of software programs that were designed to be sensitive to level of functioning and to reinforce memory, speed and accuracy have resulted in enduring cognitive gains. This fits well with the positive psychology finding (Abuhamden \& Csikszentmihalyi, 2012) that challenges that are neither too difficult nor too easy enhance enjoyment, particularly when the competition between relatively balanced opponents in an endeavor lend an element of suspense about outcome.

In positive psychotherapy we also need to include bibliotherapy. In addition to books mentioned above, Davidson's breakthrough research is delightfully presented in his superb book (2012) The Emotional Life of Your Brain. This book is an invaluable source for clinicians and consumers as a primer on the growing field of affective neuroscience. Begley's book (2007), Train Your Mind Change Your Brain, can also help educate on neuroplasticity. To be entertained plus educated, Why Zebras Don't Get Ulcers by Sapolsky can increase motivation to maximize psychotherapy to master stress. Also valuable in positive psychotherapy are: Good Business by Csikszentmihalyi; Social Intelligence by Goleman; and Authentic Happiness by Seligman.

In summary, positive psychologists need to encourage and empower people to use powerful non-pharmacological interventions that are associated with positive neuroplasticity. These include but may not be limited to aerobic exercise; combining aerobic and cognitive exercises; restorative sleep; adequate treatment of depression; stress reduction; techniques that promote enduring happiness; reducing inflammation; social influences; task specific training; cognitive behavioral techniques; meditation; and computerized cognitive training that reinforces memory and speed, is intensely focused on auditory and verbal processing and targets a specific brain system. As positive psychologists we need to motivate, educate and empower our people to drive neuroplasticity in a positive direction. Using evidence-based efforts we can help strengthen trends toward increases in wellbeing.

We are privileged that we are able to appreciate the gains reported in human intelligence across the centuries. And we're gifted to see the human lifespan extend beyond what might have been anticipated. Still, the increase in the aged with the ages has included a raft of lifestyle illnesses that could take us down like a house of cards. As positive psychologists, we need to use the encouraging and empowering evolving affective 
neuroscience to reinforce awareness, efforts and successive approximations in healthy lifestyle choices so that we are informed participants that facilitate the growth of human intelligence along with vigorous longevity. Let us unite in the marriage of neuroplastic potential and positive psychology to maximize human potential at any age with dignity, health and joie de vivre for everyone in ways that can simultaneously improve our collective economic welfare.

\section{REFERENCES}

Abuhamden, S., \& Csikszentmihalyi, M. (2012) The importance of challenge for the enjoyment of intrinsically motivated, goal-directed activities. Personality and Social Psychology Bulletin, 38, 317-330. doi:10.1177/0146167211427147

Anderson-Hanley, C., Arciero, P. J., Brickman, A. M., Nimon, J. P., Okuma, N., Westen, S. C., Merz, M. E., Pence, B. D., Woods, J. A., Kramer, A. F., \& Zimmerman, E. A. (2012). Exergaming and older adult cognition: A cluster randomized clinical trial. American Journal of Preventive Medicine, 42, 109-119. doi:10.1016/j.amepre.2011.10.016

Angevaren, M., Aufdemkampe, G., Verhaar, H. J. J., Aleman, A., \& Vanhees, L. (2008). Physical activity and enhanced fitness to improve cognitive function in older people without known cognitive impairment. The Chochrane Collaboration.

Antonuccio, D. L., W. G. Danton, G.Y. DeNelsky, R. Greenberg, \& J. S. Gordon. (1999). Raising Questions about Antidepressants. Psychotherapy and Psychosomatics, 68, 3-14. doi:10.1159/000012304

Audiffren, M., Tomporowski, P. \& Zagrodnik, J. (2008). Acute aerobic exercise and information processing: Energizing motor processes during a choice reaction time task. Acta Psychologica, 129, 410-419. doi:10.1016/j.actpsy.2008.09.006

Ball, K. K., Berch, D. B., Helmers, K. F., Jobe, J. B., Leveck, M. D., Mariske, M., Morris, J. N., Rebok, G. W., Smith, D. M., Tennstedt, S. L., Unverzagt, F. W., \& Willis, S. L. (2002). Effects of cognitive training interventions with older adults: A randomized controlled trial. JAMA, 288, 2271-2281. doi:10.1001/jama.288.18.2271

Beck, A. T. (2006). How an anomalous finding led to a new system of psychotherapy. Nature Medicine, 12, 1139-1141. doi:10.1038/nm1006-1139

Begley, S. (2007). Train your mind change your brain: How a new science reveals our extraordinary potential to transform ourselves. New York: Ballantine Books.

Berry, A. S., Zanto, T. P., Clapp, W. C., Hardy, J. L., Delahunt, P. B., Mahncke, H. W., \& Gazzaley, A.. (2010). The influence of perceptual training on working memory in older adults. PLOS ONE, 5, e11537. doi:10.1371/journal.pone.0011537

Burns, D. D. (1992). Feeling good: The new mood therapy. New York: Avon.

Burns, D. D. (1999). The feeling good handbook. New York: Plume.

Colcombe, S., \& Kramer, A. F. (2003). Fitness effects on cognitive functioning of older adults: A meta-analytic study. Psychological Science, 14, 125-130. doi:10.1111/1467-9280.t01-1-01430

Cramer, S. C., Sur, M., Dobkin, B. H., O’Brien, C., Sanger, T., D., Trojanowski,, J. Q., Rumsey, J. M., Hicks, R., Cameron, J., Chen, D., Chen, W. G., Cohen, L. G., deCharms, C., Duffy, C. J., Eden, G. F., Fetz, E. E., Filart, R., Freund, M., Grant, S. J., Haber, S., Kalivas, P. W., Kolb, B., Kramer, A. F., Lynch, M., Mayberg, H., McQuillen, P. S., Nitkin, R., Pascual-Leone, A., Reuter-Lorenz, P. C., Schiff, N., Sharma, A., Shekim, L., Stryker, M., Sullivan, E. V., \& Vinogradov., S. (2011). Harnessing neuroplasticity for clinical applications. Brain. 134, 1591-1609. doi:10.1093/brain/awr039

Csikszentmihalyi, M. (1997). Finding flow: The psychology of engagement with everyday life. New York: Basic Books.

Csikszentmihalyi, M. (2003). Good business: Leadership, flow and the making of meaning. New York: Penguin Books.

Davidson, R. J., \& Begley, S. (2012). The emotional life of your brain: How its unique patterns affect the way you think, feel, and live, and how you can change them. New York: Hudson Street Press.
Davidson, R., Kabat-Zinn. J., Schumacher, J., Rosenkranz, M., Muller, D, Santorelli, S., Urbanowski, F., Harrington, A., Bonus, K., \& Sheridan, J. (2003). Alterations in brain and immune function produced by mindfulness meditation. Psychosomatic Medicine, 65, 564 570. doi:10.1097/01.PSY.0000077505.67574.E3

Davidson, R. J., \& Lutz, A. (2008). Buddha's brain: Neuroplasticity and meditation. IEEE Signal Processing Magazine, 25, 176-174. doi:10.1109/MSP.2008.4431873

Diamond, M. C. (1988). Enriching heredity: The impact of the environment on the anatomy of the brain. New York: The Free Press.

Diamond, M. C., \& Hopson, J. (1998). Magic trees of the mind: How to nurture your child's intelligence, creativity, and healthy emotions from birth through adolescence. New York: Plume.

Diamond, M. C., Johnson, R., \& Ingham, C. (1971). Brain plasticity induced by environment and pregnancy. International Journal of Neuroscience, 2, 171-178. doi:10.3109/00207457109146999

Diamond, M., Johnson, R., Protti, A., Ott, C., \& Kajisa L. (1984). Plasticity in the 904-day-old male rat cerebral cortex. Experimental Neurology, 87, 309-317. doi:10.1016/0014-4886(85)90221-3

Diamond, M. C., Scheibel, A., Murphy Jr., G., \& Harvey, T. (1985). On the brain of a scientist: Albert Einstein. Experimental Neurology, 88, 198-204. doi:10.1016/0014-4886(85)90123-2

Edwards, J. D., Myers , C., Ross, L. A., Roenker, D. L., Cissell, G. M., McLaughlin, A. M., \& Ball, K. K. (2009). The longitudinal impact of cognitive speed of processing training on driving mobility. The Gerontologist, 49, 485-494. doi:10.1093/geront/gnp042

Duckworth, A. L., Steen, T. A., \& Seligman, M. E. P. (2005). Positive psychology in clinical practice. Annual Reviews of Clinical Psychology, 1, 629-651. doi:10.1146/annurev.clinpsy.1.102803.144154

Ellis, A. (2005). Why I (really) became a therapist. Journal of Clinical Psychology, 61, 945-948. doi:10.1002/jclp.20166

Ellis, A. (1987). The impossibility of achieving consistently good mental health. American Psychologist, 42, 364-375. doi:10.1037/0003-066X.42.4.364

Ellis, A, \& Harper, R. (1975). A new guide to rational living. Englewood Cliffs, NJ: Prentice-Hall.

Eriksson, P., Perfilieva, E., Bjőrk-Eriksson, T., Alborn, A., Nordborg, C., Peterson, D., \& Gage, F. H. (1998). Neurogenesis in the adult human hippocampus. Nature America, Inc. Medicine.Nature.com

Eyler, L. T., Sherzai, A., Kaup, A. R., \&. Jeste, D.V. (2011). A review of functional brain imaging correlates of successful cognitive aging. Biological Psychiatry, 70, 115-122. doi:10.1016/j.biopsych.2010.12.032

Flynn, J. R. (1984). The mean IQ of Americans: Massive gains 1932 to 1978. Psychological Bulletin, 95, 29-51. doi: 10.1037/0033-2909.95.1.29

Flynn, J. R. (1987). Massive IQ gains in 14 nations: What IQ tests really measure. Psychological Bulletin, 101, 171-191. doi:10.1037/0033-2909.101.2.171

Gage, F. (2002). Neurogenesis in the adult brain. The Journal of Neuroscience, 22, 612-613.

Goh, J. O., \& Park, D. C. (2009). Neuroplasticity and cognitive aging: The scaffolding theory of aging and cognition. Restorative Neurology and Neuroscience, 27, 391-403.

Goldapple, K., Segal, Z., Garson, C., Lau, M., Bieling, P., Kennedy, S., \& Mayberg, H. (2004). Modulation of cortico-limbic pathways in major depression: Treatment-specific effects of cognitive behavioral therapy. Archives of General Psychiatry, 61, 34-41. doi:10.1001/archpsyc.61.1.34

Goleman, D. (2006). Social intelligence: The new science of human relationships. New York: Bantam.

Guzman-Marin, R., \& McGinty, D. (2006). Sleep deprivation suppresses adult neurogenesis: Clues to the role of sleep in brain plasticity. Sleep and Biological Rhythms, 4, 27-34. doi:10.1111/j.1479-8425.2006.00203.x

Gregg, J., Pace-Schott, E., Stickgold, R., \& Otto, M. (2004). Cognitive behavior therapy and parmacotherapy for insomnia: A randomized controlled trial and direct comparison. Archives of Internal Medicine, 164, 1888-1896. doi:10.1001/archinte.164.17.1888

Jessberger, S., \& Gage, F. H. (2008). Stem-cell-associated structural and functional plasticity in the aging hippocampus. Psychology \& 
Aging, 23, 684-691. doi:10.1037/a0014188

Jobe, J. B., Smith, D. M., Ball, K. K., Tennstedt, S. L., Marsiske, M., Morris, J. N., Helmers, K. F., Leveck, M. D., \& Kleinman, K. (2001). ACTIVE: A cognitive intervention trial to promote independence in older adults. Controlled Clinical Trials, 22, 453-479. doi:10.1016/S0197-2456(01)00139-8

Kempermann, G., Gast, D., \& Gage, F. H. (2002). Neuroplasticity in old age: Sustained fivefold induction of hippocampal neurogenesis by long-term environmental enrichment. Annals of Neurology, 52, 135-143. doi:10.1002/ana.10262

Kohman, R. A., \& Rhodes, J. S. (2012). Neurogenesis, inflammation and behavior. Brain, Behavior, and Immunity, 27, 22-32. doi:10.1016/j.bbi.2012.09.003.

Lojovich, J. M. (2010). The relationship between aerobic exercise and cognition: Is movement medicinal? Journal of Head Trauma Rehabilitation, 25, 184-192. doi:10.1097/HTR.0b013e3181dc78cd

Mahncke, H., Bronstone, A., \& Michael, M. (2006). Brain plasticity and functional losses in the aged: Scientific bases for a novel intervention. Progress in Brain Research, 157, 81-109. doi:10.1016/S0079-6123(06)57006-2

Mahncke, H., Connor, B., Appelman, J., Ahsanuddin, O., Hardy, J., Joyce, N., Boniske, T., Atkins, S., \& Merzenich. M. (2006a). Memory enhancement in healthy older adults using a brain plasticitybased training program: A randomized, controlled study. Proceedings of the National Academy of Science USA, 103, 12523-12528. doi:10.1073/pnas.0605194103

Malkasian, D., \& Diamond, M. C. (1971). The effect of environmental manipulation on the morphology of the neonatal rat brain. International Journal of Neuroscience, 2, 161-170. doi:10.3109/00207457109146998

Pereira, A. C., Huddleston, D. E., Brickman, A. M., Sosunov, A. A., Hen, R., McKhann, G. M., Sloan, R., Gage, F. H., Brown, T. R., \& Small, S. A. (2007). An in vivo correlate of exercise-induced neurogenesis in the adult dentate gyrus. Proceedings of the National Academy of Sciences of the USA, 104, 5638-5643. doi:10.1073/pnas.0611721104

Rabipour, S., \& Raz, A. (2012). Training the brain: Fact and fad in cognitive and behavioral remediation. Brain and Cognition, 79, 159179. doi:10.1016/j.bandc.2012.02.006

Rosano, C., Marsland, A. L., \& Gianaros, P. J. (2012). Maintaining brain health by monitoring inflammatory processes: A mechanism to promote successful aging. Aging and Disease, 3, 16-33.

Sapolsky, R. M. (2004). Why zebras don't get ulcers: The acclaimed guide to stress, stress-related diseases, and coping (3rd ed.). New York: Henry Holt.

Sartori, A. C., Vance, D. E., Slater, L. Z., \& Crowe, M. (2012). The impact of inflammation on cognitive function in older adults: Implications for healthcare practice and research. Journal of Neuroscience Nursing, 44, 206-217. doi:10.1097/JNN.0b013e3182527690

Seligman, M. E. P. (2002). Authentic happiness: Using the new positive psychology to realize your potential for lasting fulfillment. New York: Free Press.
Seligman, M. E. P., \& Csikszentmihalyi, M. (2000). Positive psychology: An introduction. American Psychologist, 55, 5-14. doi:10.1037/0003-066X.55.1.5

Seligman, M. E. P, Rashid, T., \& Parks, A. C. (2006). Positive psychotherapy. American Psychologist, 61, 774-788. doi:10.1037/0003-066X.61.8.774

Seligman, M. E. P., Steen, T. A., Park, N., \& Peterson, C. (2005). Positive psychology progress: Empirical validation of interventions. American Psychologist, 60, 410-421. doi:10.1037/0003-066X.60.5.410

Sheline Y., Sanghavi, M., Mintun, M., \& Gado, M. (1999). Depression but not age predicts hippocampal volume loss in medically healthy women with recurrent depression. Journal of Neuroscience, 19, 5034-5043.

Snyder, J., Glover, L., Sanzone, K., Kamhi, F., \& Cameron, H. (2009). The effects of exercise and stress on the survival and maturation of adult-generated granule cells. Hippocampus, 19, 898-906. doi:10.1002/hipo.20552

Smith, G. E., Housen, P., Yaffe, K., Ruff, R., Kennison, R. F., Mahncke, H. W. et al. (2009). A cognitive training program based on principles of brain plasticity: Results from the improvement in memory with plasticity-based adaptive cognitive training (IMPACT) study. Journal of the American Geriatrics Society, 57, 594-603. doi:10.1111/j.1532-5415.2008.02167.x

Stickgold, R. (2005). Sleep-dependent memory consolidation. Nature, 437, 1272-1278. doi:10.1038/nature04286

Tang, Y.-Y., Lu, Q., Fan, M., Yang, Y., \& Posner, M. I. (2012). Mechanisms of white matter changes induced by meditation. Proceedings of the National Academy of Sciences, 109, 10570-10574. doi:10.1073/pnas.1207817109

Uylings, H. B. M., Kuypers, K., Diamond, M. C., \& Veltman, W. A. M. (1978). The effects of differential environments on plasticity of cortical pyramidal neurons in adult rats. Experimental Neurology, 68, 158-170.

Wagner, U., Gais, S., Halder, H., Veriger, R., \& Born, J. (2004). Sleep inspires insight. Nature, 427, 352-355. doi:10.1038/nature02223

Wolinsky, F. D., Vander Weg, M. W., Martin, R., Frederick, W., Unverzagt, F. W., Ball, K. K., Jones, R. N., \& Tennstedt, S. L. (2009). The ACTIVE cognitive training interventions and the onset of and recovery from suspected clinical Depression. Journal of Gerontology, 64A, 468-472. doi:10.1093/gerona/gln044

Zhou, X., \& Merzenich, M. M. (2009). Developmentally degraded cortical temporal processing restored by training. Nature Neuroscience, 12, 26-28. doi:10.1038/nn.2239

Zhu, B., Dong, Y., Xu, Z., Gompf, H. S., Ward, S. A. P., Xue, Z., Miao, C, Zhang, Y., Chamberlin, N. L., \& Xie. Z. (2012). Sleep disturbance induces neuroinflammation and impairment of learning and memory. Neurobiology of Disease, 19, 898-906.

Zucconi, G. G., Cipriani, S., Balgkouranidou, I., \& Scattoni, R. (2006). "One night" sleep deprivation stimulates hippocampal neurogenesis. Brain Research Bulletin, 69, 375-381.

doi:10.1016/j.brainresbull.2006.01.009 